\title{
Nos CAMINHOS DA FOLIA: UM PERCURSO DE (RE)CONHECIMENTO NA ESCOLA
}

\author{
Daniela Vergueiro Rodrigues
}

Algumas práticas escolares reproduzem situações de exclusão e violência, marcando não só o percurso escolar como também a vida de alunos. Este trabalho consiste em um estudo sobre a criação de um grupo, tendo como tema a Folia de Reis, dentro de uma Escola Municipal do Rio de Janeiro, por iniciativa de um grupo de alunos até então excluídos do processo de alfabetização. A "Folia das Crianças" permitiu o reconhecimento dos alunos enquanto sujeitos, modificando as relações sociais das crianças e jovens e garantindo-lhes a construção de um novo percurso em suas vidas.

\section{BANCA:}

Maria Inês Garcia de Freitas Bittencourt (Orientadora)

Luciana Vieira Caliman

Solange Jobim e Souza

Data da defesa: 05/03/2009 